\title{
CAPTCHA - Security Affecting User Experience
}

\author{
Ruti Gafni \\ The Academic College of \\ Tel-Aviv-Yaffo and \\ The Open University of Israel, Israel \\ rutigafn@mta.ac.il
}

\author{
Idan Nagar \\ The Academic College of \\ Tel-Aviv-Yaffo, Israel
}

Idan.nagar@gmail.com

\begin{abstract}
CAPTCHA - Completely Automated Public Turing test to tell Computers and Humans Apart - is a test with the aim to distinguish between malicious automatic software and real users in the era of Cyber security threats. Various types of CAPTCHA tests were developed, in order to address accessibility while implementing security. This research focuses on the users' attitudes and experiences related to use of the different kinds of tests. A questionnaire accompanied by experiencing five different CAPTCHA tests was performed among 212 users. Response times for each test and rate of success were collected automatically. The findings demonstrate that none of the existing tests are ideal. Although the participants were familiar with the Text-based test, they found it the most frustrating and non-enjoyable. Half of the participants failed in the Arithmetic-based test. While most of the participants found the picture and game based test enjoyable, their response time for those tests was the largest. The age factor was encountered as influencing both the attitude of the user and the performance, while younger users are more tolerant, have a better success rate, and are faster, the elder users found the tests annoying and time-consuming.
\end{abstract}

Keywords: CAPTCHA, Cyber Security, User Experience

\section{Introduction}

In the era of Cyber threats, it is very important to understand if the user trying to access a Website is a real person or a "bot", a malicious automated program. In order to decide whether to allow the access, the first CAPTCHA test was invented in 2000 by John Langford, Nicholas J. Hooper and Luis Von Ahn and it is still used (Singh \& Pal, 2014). CAPTCHA is an acronym for "Completely Automated Public Turing test to tell Computers and Humans Apart".

The CAPTCHA test performs an authentication process, called a "challenge-response authentication", because it presents a challenge to the user, and only when it is solved, the right to access the Website is given (Ling-Zi \& Yi-Chun, 2012). It is difficult and almost impossible for bots to

Material published as part of this publication, either on-line or in print, is copyrighted by the Informing Science Institute.

Permission to make digital or paper copy of part or all of these works for personal or classroom use is granted without fee provided that the copies are not made or distributed for profit or commercial advantage AND that copies 1) bear this notice in full and 2) give the full citation on the first page. It is permissible to abstract these works so long as credit is given. To copy in all other cases or to republish or to post on a server or to redistribute to lists requires specific permission and payment of a fee. Contact Publisher@InformingScience.org to request redistribution permission. solve these challenges (Saini \& Bala, 2013). The operation is similar to a reverse "Turing Test" where the CAPTCHA test acts like a judge and on the other side stands the "user", which may be human or not. CAPTCHA tests must be, on the one hand, very easy for the user in order to pass, and, on the other hand, very difficult for the bots to pass. The conflict between approachability and protection in the Internet 
world is a complex issue, dealing with the necessity to allow a wide range of different users to access the desired Website, but preventing the access of malicious elements.

Cyber threats became abundant, and the attempts to reach computers by unauthorized agents are growing. For example, according to Symantec (2011), 75.8\% of the emails sent are "spam", where $82.2 \%$ of them are originated by bots. Therefore, CAPTCHA implementations can be found on more than 3.5 million sites globally, in all kind of Websites, like sites for fill-in forms, write comments, and buy tickets, and human beings solve CAPTCHA tests more than 300 million times a day (Angre, Kapadia, \& Ugale, 2015).

\section{Different Types of CAPTCHA Tests}

During the last years, several types of CAPTCHA tests were defined and developed. Below is a description of the most common different types of tests.

Text-based CAPTCHA tests - This is the most common test, called "reCAPTCHA", in which a sequence of letters and/or numbers is shown in a distorted and twisted manner, as seen in Figure 1. The user needs to identify and decipher what is shown, and type the exact sequence into a provided text-box in order to get access to the desired Webpage. This system, was originally aimed to help digitize printed text that was hard to read by OCR (Optical Character Recognition) softwares, and was acquired by Google in 2009, in order to use the "Common Wisdom" to digitize large number of manuscripts ("reCAPTCHA," n.d.).

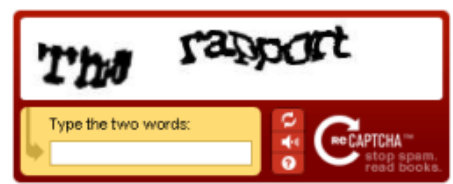

Figure 1: Text-based CAPTCHA

Audio based CAPTCHA tests - This test was developed for vision-impaired people. The user must listen to a sequence of letters and/or numbers and type the sequence in the text-box.

Pre-analysis of user behavior - In 2013, reCAPTCHA began implementing behavioral analysis of the browser's interactions with the CAPTCHA to predict whether the user is a human or a bot. This analysis, called "No CAPTCHA reCAPTCHA" (shown in Figure 2), occurs before displaying the text-based CAPTCHA and, according to the analysis, when there are reasons to think the user might be a bot, a more difficult test is presented to the user. By end of 2014 this mechanism started to be rolled out to most of the public Google services ("reCAPTCHA," n.d.).

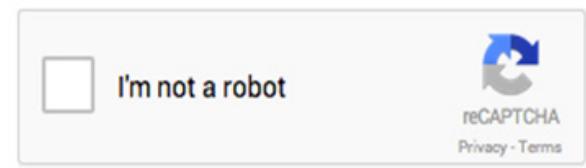

Figure 2: No CAPTCHA reCAPTCHA

Arithmetic operation based CAPTCHA tests - In this type of test, as shown in Figure 3, the sequence shown to the user contains a very basic arithmetic operation, i.e., " $1+3=$ =", which can be performed by almost every human being. The user needs to enter the result of the operation into a text box. 


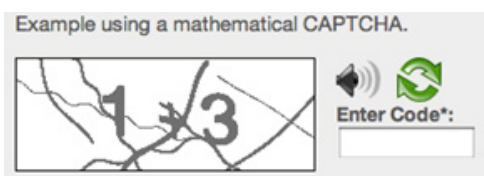

Figure 3: Arithmetic operation CAPTCHA

Picture based CAPTCHA tests - In this test a number of pictures are shown to the user, with a simple question, as shown in Figure 4. The user must identify the pictures and select the one that is the correct answer to the question. There is no need to write any text.

There are some variations of the picture-based CAPTCHA. For example, a sliding test was developed, where a contorted picture is shown, and the user needs to slide the picture till it shows a recognizable picture (Figure 5).

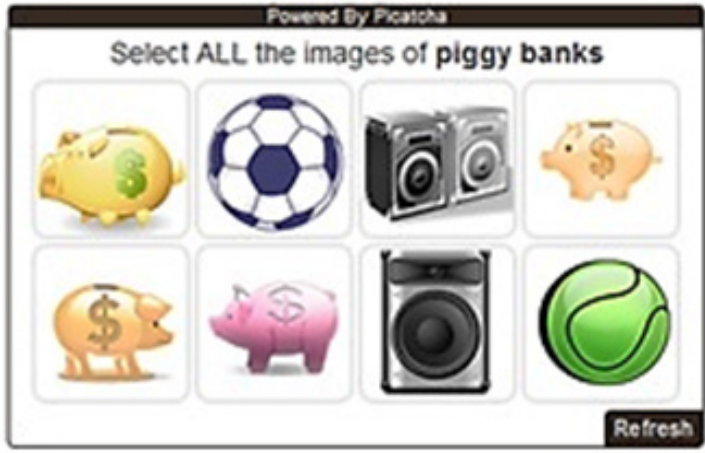

Figure 4: Picture based CAPTCHA

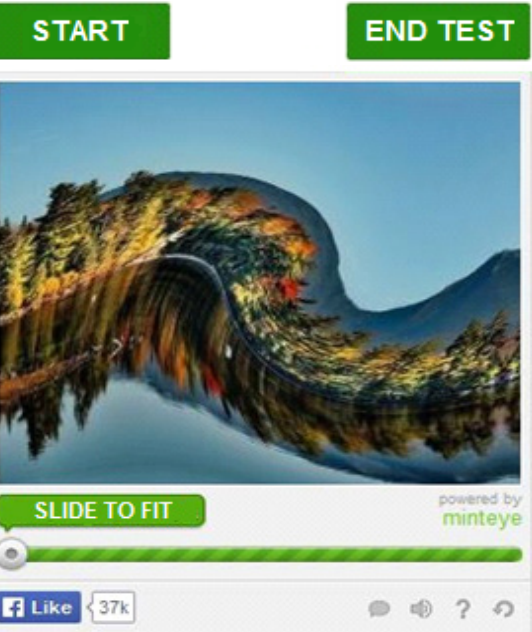

Figure 5: Twisted Picture based CAPTCHA

Game based CAPTCHA tests - User experience and gamification are some of the "buzzwords" in the last years (Deterding, Dixon, Khaled, \& Nacke, 2011). In order to encourage the users to perform tedious but substantial tasks, the activity is wrapped with a joyful function. This was translated in the CAPTCHA fields into different kinds of games, like puzzles or interactive games (Mohamed et al., 2013). In Figure 6, an example of a game can be seen, where the user needs to drag the food to the baby's mouth.

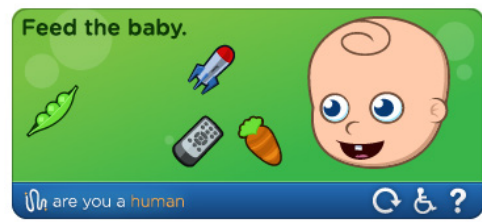

Figure 6: Game based CAPTCHA

Many studies have been conducted on CAPTCHA tests, some focusing on the security analysis (Azad, 2013; Tayade \& Bartere, 2015; Wang, Zhang, Jiang, \& Song, 2014), others on differences between types of tests (Bhalani, \& Mishra, 2015; Foley, 2012; Singh \& Pal, 2014; Veesam \& Babu, 2015), and others examined the combination between security and user friendliness (Gossweiler, Kamvar, \& Baluja, 2009). Few focused on the user experience and their opinion on CAPTCHA tests (Fidas, Voyiatzis, \& Avouris, 2011; Tangmanee \& Sujarit-apirak, 2013). This research deals with the differences between various CAPTCHA tests influencing the user experi- 
ence and their actual performance and success. This paper includes a theoretical background about previous studies in this field, the presentation of the research questions, explanation of the methodology used to examine these questions, exhibition of the results, a discussion about the significance of the results, and finally the conclusions from the research.

\section{Theoretical Background}

In order to keep and increase the user traffic into Websites, their designers are trying to leverage the user experience. However, because of the Cyber security threats, the access to the Websites must be controlled, and this is performed, mostly, by using CAPTCHA tests.

User experience is described by Bevan's (2009) paper as including all emotions, beliefs, preferences, conceptions, psychological and physical reactions, behaviors, and achievements occurring before, during, and after usage. Difficulties in performing a task diminish the user experience.

The different types of CAPTCHA tests described above have some disadvantages.

In the text-based type, the user experiences a difficulty deciphering and identifying the characters due to the font type and the blurring of the characters displayed (Singh \& Pal, 2014). Furthermore, if the distortion is not intense, recent developed bots may have the ability to recognize the character sequence using optical character recognition (OCR) software (Singh \& Pal, 2014). Azad (2013) proposed to raise text-based CAPTCHA security by adding more "noise" and by increasing the level of distortion of the presented characters, as well as by aligning the characters more closely; yet this would make it more difficult for users to identify the characters, causing more mistakes, and, therefore, reducing user experience.

Text-based CAPTCHA requires the deciphering of a sequence of deformed characters, most of which are in English, therefore users need to be able to read Latin letters. For Thai Internet users, English is a less familiar language, so for them tests in Thai could prove to be a more suitable option (Tangmanee \& Sujarit-apirak, 2013). The study of Fidas, Voyiatzis, and Avouris (2011) demonstrates that Greek users have also shown difficulties using CAPTCHA. These findings support the argument that users whose mother tongue is not English frequently find CAPTCHA challenging (Bursztein, Bethard, Fabry, Mitchell, \& Jurafsky, 2010). Hsu and Lee (2011) found that older Internet users from Taiwan show greater difficulty in passing a text-based CAPTCHA in comparison to younger users.

According to Foley's study (2012), the text-based CAPTCHA test has many accessibility problems, especially for visually-impaired or blind users, who find the distorted text difficult to decipher, and sometimes even completely impossible to see. This means that they are not able to pass this test.

In the audio-based type, the sound clips played are based on the English language, and therefore the user must understand English (Singh \& Pal, 2014). In addition, it may be problematic to recognizing similar-sounding letters. Moreover, the text is played together with "noise", in order to pose a challenge to bots, and thus, this solution is not ideal, as it poses a problem for users who are hard of hearing or vision. In addition, according to Onwudebelu, Sanjo, Obi and Alaba (2010), while audio-based CAPTCHA tests are more commonly used for the visually-impaired, they do not provide full accessibility, and are even characterized by a lower degree of security.

Since picture-based CAPTCHA tests, are entirely based on image recognition, blind or visuallyimpaired users struggle to pass it as well (Foley, 2012). Although picture-based CAPTCHA tests were presented in order to overcome the limited security level that exists in the text-based tests, these tests still suffer from a number of problems, such as user-unfriendliness. According to Ahn, Kim and Kim (2013), a picture-based CAPTCHA test is one that requires recognition and selection of images with a similar meaning out of a sequence of images. Such a task may cause the 
user confusion, as the image can sometimes be interpreted as having other meanings. In addition, the majority of these tests require distinction between many images in every test. Similarly, there is another type of picture-based tests, which requires the distinction of which image in a sequence of images has the exceptional meaning. In order to cope with this difficulty, Ahn et al. (2013) proposed an 'upgrade' to this picture-based test; comprising a single image next to numerous verbal answers, enabling the user to provide an answer in a faster and more convenient manner. The findings of their study demonstrate that this method yielded a higher rate of correct answers when compared to the normal image recognition test. In order to improve user friendliness, Gossweiler et al. (2009) proposed another alternative to the picture-based CAPTCHA test, which requires the identification of pictures with a common denominator.

Onwudebelu et al. (2010) describe the users' attitude towards the use of CAPTCHA tests as a nuisance. Some users feel threatened by the test, irritated and frustrated, as they were unable to understand why they must pass it. In addition, other users reported that the text displayed in the test was too unclear, and they struggled to solve it. Furthermore, most of them reported that the tests slow them down and interfere with their activity on Websites.

Bursztein et al. (2010) examined the effects of the participants' age on the success rate. They found that the older users' response times were longer, however they made fewer mistakes. Fidas et al. (2011), who examined the users' attitude towards the CAPTCHA test, found no significant correlation between age or gender and the users' positions, indicating that the antagonism was consistent for all participants.

Aside from accessibility difficulties, frustration, and poor user experience (Ghazarian, 2014), user abandonment and a drop of Internet conversion rates are additional consequences of various CAPTCHA tests suffering from user-unfriendliness (Mujumdar \& Polisetti, 2011).

\section{Research Questions and Hypotheses}

The objective of this study is to investigate the differences between various CAPTCHA tests and examine how they affect the user experience.

RQ1: Are there any differences between the user experiences using the various CAPTCHA tests? H1: The user experience will be more positive after taking the picture based or game based CAPTCHA tests.

This hypothesis is based on the gamification trend, the use of game design elements in non-game contexts (Deterding et al., 2011), and the difficulties shown by previous research about tests based on text (Foley, 2012; Singh \& Pal, 2014).

RQ2: Are there any differences in the position towards using the same test in the future?

H2: The readiness for future use of game based CAPTCHA test will be higher.

Although users are conscious and aware of the Cyber threats, they do not like to perform Sisyphean tasks. In this case, the gamification trend (Deterding et al., 2011) can help to convince users to participate.

RQ3: Is the success rate different in the various CAPTCHA tests?

H3: The success rate will be lower in tests requiring the identification of letters and numbers, like the text based and arithmetic tests.

This hypothesis is based on the difficulties users cope with when performing the text and numbers based CAPTCHA tests, shown by previous research (Foley, 2012; Singh \& Pal, 2014). 
RQ4: Is the response time different in the various CAPTCHA tests?

H4: The response time will be significantly shorter in the 'No CAPTCHA' test compared to the other types of tests.

In the "No CAPTCHA" test, the user only needs to check the box. Only in case the browser believes the user is not human, the test is more complicated. The experiment was performed by real human users, so the probability that the browser will assume the person to be a bot, is really low.

Users have difficulties in comprehending distorted texts, as shown by previous studies (Singh \& Pal, 2014; Foley, 2012), and the game test, although more playful, demands more activities to perform.

RQ5: Are there any differences about the attitude or performance of the various CAPTCHA tests, regarding to age?

H5.1: Positive correlation will be found between the age of the user and the aversion and impatience towards access security tests.

H5.2: Positive correlation will be found between the age of the user and response time.

H5.3: Negative correlation will be found between the age of the user and success rate.

\section{Methodology}

In order to collect the data used in this research, a questionnaire and an experiment were created, which included the actual usage of five different types of CAPTCHA tests. The respondents had to perform the tests and rate their experience using them by a five-level Likeret-type scale (1 'Strongly disagree', 5 - 'Strongly agree'). Meanwhile, a specific script hidden automatically accumulated the data about the success or failure of the respondent in using the specific test and the time it took to complete the test. The combination of both research methods was based on the study conducted by Abrich, Berbenetz, and Thrope (2011), which defined the quality of user experience on whether the user was correct or not when taking a test, as well as on the level of test difficulty the user reported.

The questionnaire was composed of 11 demographic and general information questions, and other 10 questions, answered once for each test after experiencing them, so each participant had to perform five tests and answer overall to 61 questions.

The types of CAPTCHA that were examined in this research are the following:

1. Text-based CAPTCHA

2. Arithmetic operation-based CAPTCHA

3. Picture-based CAPTCHA, using the version with the slider option, developed by Minteye Company (www.minteye.com).

4. Game-based CAPTCHA, developed by Are-you-a-human Company (www.areyouahuman.com)

5. "No CAPTCHA", developed by Google Company, (www.google.com/recaptcha)

The questions and the experiment were constructed using a plug-in based on WordPress, which is a free software that can be used to create websites or blogs. The plug-in helps to create classic and advanced polls with dependent questions and publish the polls into a Web page or a post.

The questionnaire was delivered using social media like Facebook (Baltar \& Brunet, 2012). The answers were automatically and anonymously collected into a repository during one week (in December 2014), and then gathered and analyzed using IBM $®$ SPSS $®$ Statistics. 


\section{Results}

Table 1 summarizes the descriptive statistics of the 212 participants in the questionnaire and experiment. The sample for this research was composed of Israeli people, who speak and write Hebrew. They are familiar with Latin letters, but these letters are not used in the Hebrew language.

Table 1: Demographics of the survey participants

\begin{tabular}{|l|l|}
\hline $\mathbf{n}$ & 212 \\
\hline Gender & 99 men $(47 \%)$ \\
& 113 women $(53 \%)$ \\
\hline Age & 18 and under -6 participants (3\%) \\
& $19-30-141$ participants $(66 \%)$ \\
& $31-45-46$ participants $(22 \%)$ \\
& $46-59-14$ participants $(7 \%)$ \\
& 60 and above -5 participants $(2 \%)$ \\
\hline Education & 21 high-school (10\%) \\
& 118 undergraduate students $(56 \%)$ \\
& 46 bachelor degree (22\%) \\
& 27 master and higher degrees (13\%) \\
\hline
\end{tabular}

During the experiment, the participants were asked to rate their agreement ( 1 - 'Strongly disagree', 5 - 'Strongly agree') with different statements in the questionnaire.

Before performing the tests, the respondents were asked about their familiarity and position towards CAPTCHA tests, according to their previous experiences. The familiarity of the respondents with the different kinds of CAPTCHA tests is presented in Table 2. As seen, the text-based CAPTCHA is the most familiar to the users, and the arithmetic operation based one is also known. Most of the users are not so familiar with the other three types. The "No CAPTCHA" based test was very new at the time the data was gathered.

Table 2: Familiarity with the CAPTCHA test (1 - ' Never', 5 - 'Very often')

\begin{tabular}{|l|c|c|}
\hline \multicolumn{1}{|c|}{ CAPTCHA type } & Mean $(\mathbf{n = 2 1 2})$ & SD \\
\hline 1. Text based & 3.91 & 0.96 \\
\hline 2. Arithmetic operation based & 2.27 & 1.26 \\
\hline 3. Picture based & 1.15 & 0.55 \\
\hline 4. Game based & 1.11 & 0.45 \\
\hline 5. "No CAPTCHA" based & 1.58 & 1.08 \\
\hline
\end{tabular}

The general position towards CAPTCHA is summarized in Table 3. As can be seen, the users understand the purpose of the tests (4.19), but this understanding does not cause them to feel protected (2.83). Moreover, most of the users don't like to use the CAPTCHA tests. It's important to emphasize, that according to Table 2 , most of the users are familiar only with the text-based and arithmetic-based tests. 
Table 3: General position towards CAPTCHA tests

\begin{tabular}{|l|c|c|}
\hline \multicolumn{1}{|c|}{ Statement } & $\begin{array}{c}\text { Mean } \\
(\mathbf{n = 2 1 2})\end{array}$ & SD \\
\hline $\begin{array}{l}\text { "I understand the meaning and the purpose of } \\
\text { CAPTCHA tests" }\end{array}$ & 4.19 & 1.09 \\
\hline $\begin{array}{l}\text { "I feel frustrated / I hate it" } \\
\text { "I feel that I spend too much time on it" }\end{array}$ & 3.05 & 1.36 \\
\hline $\begin{array}{l}\text { "I feel protected / safe" } \\
\text { "I prefer something more comfortable instead of this } \\
\text { test / I prefer it would not exist" }\end{array}$ & 3.70 & 1.20 \\
\hline
\end{tabular}

\section{Examination of User Experience}

After performing each of the CAPTCHA tests, the participants were asked to rate their agreement with the statements regarding some questions about their user experience. Table 4 specifies the items means and standard deviation, and the constructs definition according to the reliability, measured by Cronbach's alpha.

Table 4: User experience constructs definition

\begin{tabular}{|c|c|c|c|c|c|}
\hline Question & Statement & $\begin{array}{l}\text { Mean } \\
\text { (SD) }\end{array}$ & $\begin{array}{l}\text { Cronbach's } \\
\text { alpha }\end{array}$ & Construct & $\begin{array}{l}\text { Mean } \\
\text { (SD) }\end{array}$ \\
\hline \multirow{3}{*}{$\begin{array}{l}\text { "How would you de- } \\
\text { scribe your feeling } \\
\text { after taking this } \\
\text { CAPTCHA test?" }\end{array}$} & $\begin{array}{l}\text { "Frustrating - the test was } \\
\text { difficult and unclear" }\end{array}$ & $\begin{array}{c}3.94 \\
(1.28)\end{array}$ & \multirow[b]{2}{*}{.802} & \multirow[b]{2}{*}{ Frustration } & \multirow{2}{*}{$\begin{array}{l}3.86 \\
(1.23)\end{array}$} \\
\hline & $\begin{array}{l}\text { "A waste of time - It took too } \\
\text { much time to do it" }\end{array}$ & $\begin{array}{c}3.78 \\
(1.40)\end{array}$ & & & \\
\hline & $\begin{array}{l}\text { "Comfortable/Enjoyable - It } \\
\text { was a nice test" }\end{array}$ & $\begin{array}{c}2.94 \\
(1.49)\end{array}$ & Separated & Enjoyable & $\begin{array}{l}2.94 \\
(1.49)\end{array}$ \\
\hline \multirow{3}{*}{$\begin{array}{l}\text { "If you have to take } \\
\text { this CAPTCHA test } \\
\text { again, } \\
\text { What will your posi- } \\
\text { tion be towards this } \\
\text { test?" }\end{array}$} & $\begin{array}{l}\text { "I would rather do it again - } \\
\text { since it's easy and clear" }\end{array}$ & $\begin{array}{c}3.07 \\
(1.48)\end{array}$ & \multirow{3}{*}{.954} & \multirow{3}{*}{$\begin{array}{l}\text { Readiness for } \\
\text { future use }\end{array}$} & \multirow{3}{*}{$\begin{array}{l}3.05 \\
(1.43)\end{array}$} \\
\hline & $\begin{array}{l}\text { "I would rather do it again - } \\
\text { since it takes only a short } \\
\text { time to do it " }\end{array}$ & $\begin{array}{c}3.09 \\
(1.48)\end{array}$ & & & \\
\hline & $\begin{array}{l}\text { "I would rather do it again - } \\
\text { since it's nice and comforta- } \\
\text { ble" }\end{array}$ & $\begin{array}{c}3.00 \\
(1.52)\end{array}$ & & & \\
\hline \multirow{3}{*}{$\begin{array}{l}\text { "If you have to take } \\
\text { this CAPTCHA test } \\
\text { again, } \\
\text { What will your posi- } \\
\text { tion be towards the } \\
\text { website that displays } \\
\text { this test?" }\end{array}$} & $\begin{array}{l}\text { "My position will be posi- } \\
\text { tive" }\end{array}$ & $\begin{array}{c}2.89 \\
(1.34) \\
\end{array}$ & Deleted & & \\
\hline & $\begin{array}{l}\text { "I will not cooperate with this } \\
\text { site - I will leave this site } \\
\text { immediately" }\end{array}$ & $\begin{array}{c}4.29 \\
(1.07)\end{array}$ & \multirow[b]{2}{*}{.904} & \multirow{2}{*}{$\begin{array}{l}\text { Unwillingness } \\
\text { to use the } \\
\text { Website }\end{array}$} & \multirow{2}{*}{$\begin{array}{l}4.28 \\
(1.03)\end{array}$} \\
\hline & $\begin{array}{l}\text { "I will not cooperate with this } \\
\text { site - I will not perform ac- } \\
\text { tions such as registration, } \\
\text { buying, etc." }\end{array}$ & $\begin{array}{c}4.26 \\
(1.09)\end{array}$ & & & \\
\hline
\end{tabular}


Finally, four different constructs were defined for "User Experience":

1) Frustration

2) Enjoyable

3) Readiness for future use

4) Unwillingness to use the Website

The mean attitude towards those constructs was compared for each of the CAPTCHA tests, as reported in Table 5. It can be seen that the "No CAPTCHA" test is the least frustrating test, but also the arithmetic-based, surprisingly, is not frustrating. The most enjoyable is the game-based test, but with a very similar rate is the picture-based.

Table 5: Comparison of the CAPTCHA types - mean and SD - User Experience

\begin{tabular}{|l|c|c|c|c|}
\hline \multicolumn{1}{|c|}{ CAPTCHA type } & Frustration & Enjoyable & $\begin{array}{c}\text { Readiness } \\
\text { for future } \\
\text { use }\end{array}$ & $\begin{array}{c}\text { Unwillingness } \\
\text { to use the } \\
\text { Website }\end{array}$ \\
\hline Text based & 3.44 & 2.00 & 2.33 & 4.21 \\
& $(1.14)$ & $(1.17)$ & $(1.11)$ & $(0.93)$ \\
\hline Arithmetic operation & 4.08 & 2.92 & 3.24 & 4.36 \\
based & $(1.10)$ & $(1.42)$ & $(1.37)$ & $(0.99)$ \\
\hline Picture based & 3.87 & 3.30 & 3.30 & 4.31 \\
& $(1.22)$ & $(1.45)$ & $(1.45)$ & $(1.02)$ \\
\hline Game based & 3.81 & 3.33 & 3.11 & 4.30 \\
& $(1.21)$ & $(1.41)$ & $(1.37)$ & $(1.02)$ \\
\hline “No CAPTCHA" based & 4.11 & 3.13 & 3.30 & 4.20 \\
& $(1.35)$ & $(1.59)$ & $(1.55)$ & $(1.17)$ \\
\hline
\end{tabular}

The user experience constructs were compared for each CAPTCHA test against all the others, using t-tests, and for each pair of the tests. Table 6 presents the most interesting and meaningful results of these comparisons.

Table 6: Comparison between user experiences constructs between CAPTCHA tests

\begin{tabular}{|c|c|c|c|c|c|c|c|}
\hline $\begin{array}{l}\text { User Experience con- } \\
\text { struct }\end{array}$ & $\begin{array}{c}\text { CAPTCHA } \\
\text { type }\end{array}$ & $\mathbf{N}$ & $\begin{array}{c}\text { Mea } \\
\mathbf{n}\end{array}$ & SD & $\mathbf{t}$ & df & $\begin{array}{l}\text { Sig. }(2- \\
\text { tailed) }\end{array}$ \\
\hline \multirow{2}{*}{ Frustration } & Text based & 212 & 3.44 & 1.14 & \multirow{2}{*}{5.655} & \multirow{2}{*}{1058} & \multirow{2}{*}{.000} \\
\hline & All the others & 848 & 3.97 & 1.23 & & & \\
\hline \multirow{2}{*}{ Enjoyable } & Text based & 212 & 2.00 & 1.17 & \multirow{2}{*}{12.42} & \multirow{2}{*}{397} & \multirow{2}{*}{.000} \\
\hline & All the others & 848 & 3.17 & 1.47 & & & \\
\hline \multirow{2}{*}{ Enjoyable } & Picture based & 212 & 3.30 & 1.45 & \multirow{2}{*}{-.204} & \multirow{2}{*}{422} & \multirow{2}{*}{.838} \\
\hline & Game based & 212 & 3.33 & 1.41 & & & \\
\hline \multirow{2}{*}{$\begin{array}{l}\text { Readiness for future } \\
\text { use }\end{array}$} & Text based & 212 & 2.33 & 1.11 & \multirow{2}{*}{9.96} & \multirow{2}{*}{407} & \multirow{2}{*}{.000} \\
\hline & All the others & 848 & 3.24 & 1.44 & & & \\
\hline
\end{tabular}

It can be seen that, for the Frustration construct, the most frustrating is the Text-based test, which is different from all the others, while the least frustrating are the Arithmetic-based test and the "No CAPTCHA" test, in same extent, with no significant difference between them. 
For the Enjoyable construct, the most enjoyable are the Picture-based and Game-based tests, which received a similar attitude from the users, while the least enjoyable was the Text-based test.

The Readiness for future use construct received the most negative reaction in the Text-based test. There was no statistical significant difference between the Arithmetic-based, Picture-based, and "No-CAPTCHA" tests.

No significant differences were found for the construct Unwillingness to use the Website, between the different CAPTCHA tests.

Two performance metrics were examined for each test:

- Success Rate - How often do users pass the test successfully?

- Response Time - How long it takes users to complete the test?

As can be seen in Table 8, the most difficult task to perform successfully was the arithmetic based test. However, surprisingly, it was the faster one. The most successful were the "No CAPTCHA" and gamed-based, although there is no test with $100 \%$ success. The game-based and picturebased took longer than other tests to finish for the users who succeeded and pass them. In the other tests, the users who failed spent more time. According to the results, it can be seen that there are differences in the success rates of the various CAPTCHA tests.

Table 8: Comparison of the CAPTCHA types - Success Rates and Response Time

\begin{tabular}{|l|c|c|c|c|}
\hline & \multicolumn{2}{|c|}{ Success Rate } & \multicolumn{2}{c|}{ Response Time (in seconds) } \\
\hline CAPTCHA type & $\mathbf{( n = 2 1 2 )}$ & Total & Mean & SD \\
\hline \multirow{4}{*}{ Text based } & $\%$ & $69.81 \%$ & 20.17 & 13.46 \\
\cline { 2 - 5 } & Pass & 148 & 19.30 & 12.32 \\
\cline { 2 - 5 } & Fail & 64 & 22.19 & 15.71 \\
\hline \multirow{4}{*}{ Arithmetic operation based } & $\%$ & $49.53 \%$ & 9.80 & 9.12 \\
\cline { 2 - 5 } & Pass & 105 & 8.32 & 4.94 \\
\cline { 2 - 5 } & Fail & 107 & 11.24 & 11.73 \\
\hline \multirow{3}{*}{ Game based } & $\%$ & $71.70 \%$ & 25.03 & 25.34 \\
\cline { 2 - 5 } & Pass & 152 & 25.55 & 24.49 \\
\cline { 2 - 5 } & Fail & 60 & 23.70 & 27.54 \\
\hline \multirow{3}{*}{ "No CAPTCHA" } & $\%$ & $83.02 \%$ & 20.54 & 15.44 \\
\cline { 2 - 5 } & Pass & 176 & 20.99 & 16.35 \\
\cline { 2 - 5 } & Fail & 36 & 18.36 & 9.80 \\
\hline & $\%$ & $88.68 \%$ & 19.07 & 23.31 \\
\cline { 2 - 5 } & Pass & 188 & 16.84 & 15.64 \\
\cline { 2 - 5 } & Fail & 24 & 36.54 & 51.34 \\
\hline
\end{tabular}

When looking for the differences in attitudes and performance, according to the age of the participants, it can be seen that there is a significant positive correlation, measured by Spearman's rank correlation coefficient $(\mathrm{rs}=.169, \mathrm{p}=.014, \mathrm{n}=212)$, between age and impatience towards access security apps, as shown in Table 9. It can be also seen that the success rate decreases and the re- 
sponse time increases (Spearman's rank correlation coefficient - $r s=.077, \mathrm{p}=.012, \mathrm{n}=1060$ ), when the participants are elder. It's important to have a reservation on the results, giving that the frequency of the different ages is not balanced, and most of the respondents were at the 19-30 years old group.

Table 9: Differences according to age

\begin{tabular}{|l|c|c|c|c|c|}
\hline \multicolumn{1}{|c|}{ Age } & $\begin{array}{c}\mathbf{1 8} \text { and } \\
\text { under }\end{array}$ & $\mathbf{1 9 - 3 0}$ & $\mathbf{3 1 - 4 5}$ & $\mathbf{4 6 - 5 9}$ & $\begin{array}{c}\mathbf{6 0} \text { and } \\
\text { above }\end{array}$ \\
\hline Age Frequency & $6(3 \%)$ & $\begin{array}{c}141 \\
(67 \%)\end{array}$ & $\begin{array}{c}46 \\
(22 \%)\end{array}$ & $\begin{array}{c}14 \\
(7 \%)\end{array}$ & $5(2 \%)$ \\
\hline $\begin{array}{l}\text { Feeling impatient toward } \\
\text { CAPTCHA tests (Mean) }\end{array}$ & 2.17 & 2.32 & 2.52 & 3.43 & 2.6 \\
\hline $\begin{array}{l}\text { Success rate (\%) } \\
\text { [each user performed 5 tests] }\end{array}$ & $90 \%$ & $72.6 \%$ & $70.8 \%$ & $72.8 \%$ & $64 \%$ \\
\hline Pass & 27 & 512 & 163 & 51 & 16 \\
\hline Fail & 3 & 193 & 67 & 19 & 9 \\
\hline Response Time (seconds) & $\begin{array}{c}19.53 \\
(14.33)\end{array}$ & $\begin{array}{c}17.43 \\
(14.50)\end{array}$ & $\begin{array}{c}19.44 \\
(21.57)\end{array}$ & $\begin{array}{c}26.13 \\
(29.35)\end{array}$ & $\begin{array}{c}35.40 \\
(45.91)\end{array}$ \\
\hline
\end{tabular}

\section{Discussion}

The objective of this study is to investigate the differences between various CAPTCHA tests and examine how they affect user experience, success rate, and response time.

Prior to the research, the participants were familiar, mostly, with the Text-based CAPTCHA test, which is the most commonly used by the Websites. Most of the users don't like to use the CAPTCHA tests. Although they understand the purpose of the tests, they don't feel protected. It's important to emphasize that the majority of the users were not familiar with the other CAPTCHA tests, which were found, from the results of this research, as more enjoyable.

In this research, each of the participants had to cope with each one of the five CAPTCHA tests: Text based, Arithmetic based, Picture based, Game based and "No CAPTCHA" tests. They had to perform the test, meanwhile the success and response time were measured, and then answer a list of questions about their experience with each one of the tests.

This study found that there are differences in the user experiences using the various tests. In order to measure the user experience, four constructs were defined, derived from the statements of the questionnaire, and measured: 1) Frustration, 2) Enjoyable, 3) Readiness for future use, and 4) Unwillingness to use the Website.

According to the results, the most frustrating, non-enjoyable test is the Text-based CAPTCHA, and users are less ready to use it again. This is concordant to prior studies (Foley, 2012; Singh \& Pal, 2014). People have difficulties in reading and deciphering the distorted letters, and, because it is the most common test in Internet sites, they have to cope with this frustration over and over. Almost $70 \%$ of the users succeeded in performing the test, while the mean time needed in order to finish the test was about 20 seconds.

The results for the Arithmetic-based test were surprising. The hypotheses about this test were that, similar to the Text-base test, people have problems in decipher the distorted numbers, and moreover, they have to perform a simple calculation, and enter the result, an operation that needs more cognitive efforts than the Text-based test. The Arithmetic-based test was found less frustrating and more enjoyable than the Text-based and the readiness to use it in the future was greater. Moreover, the response time for the Arithmetic test was surprisingly low (mean 9.8 seconds); 
however, half of the users were wrong in the answer, and didn't pass the test. In this case, the users didn't get any reply about their success, but in a real Website test, they wouldn't be granted the admission to the site, so maybe their attitude to the test would have been different, spending more time to really understand and complete the task successfully.

The participants' attitude through the Picture-based and the Game-based tests were very similar. They were the most enjoyable tests. This was expected, since these tests are based on gamification, which aims to perform unwanted tasks in a playful and pleasant way. This finding fully supports Mohamed et al.'s (2013) study, focused on game-based type CAPTCHA tests, who claimed that the game is intended to be enjoyable, more user friendly, and specifically aimed at enhancing the user experience.

The success was greater in the Game-based test than in the Picture-based one, but the time it took to finish the task was greater in the Picture-based test. Spending more time performing the task, but receiving less successful outcomes, can indicate that the Picture-based is more difficult to the users.

The new "No CAPTCHA" test, in which the user must check a box, certifying he/she is a human being, was the least frustrating test, and the readiness of the participants to use it again the future was the highest. These results are logical, because this is the simpler test for the user.

No significant differences were found for the construct Unwillingness to use the Website, between the different CAPTCHA tests.

Thus, the $\mathrm{H} 1$ hypothesis - The user experience will be more positive after taking the picture based or game based CAPTCHA test, was accepted. The confirmation of this hypothesis supports the notion of an application of a similar type of test, which developed as a new alternative method with the main purpose of improving user friendliness, as well as the performance experience of CAPTCHA tests (Grossweiler et al., 2009).

The second hypothesis, $\mathrm{H} 2$, proposed that the readiness for future use of the Game-based CAPTCHA test will be higher than the others. The results indicate that there was no significant difference between the CAPTCHA based game and other tests types in this measure. Therefore, this hypothesis was disproved

As H3 suggests, people indeed have more difficulties in coping with texts and numbers. The Arithmetic-based test was the most difficult one, with the lowest success rate, and the second one was the Text-based test. The confirmation of this hypothesis supports the results of the study conducted by Fidas et al. (2011), who themselves confirmed the widespread notion that tests such as these are difficult for people.

The fourth research question deals with the response time. H4 suggested that the response time will be significantly shorter in the "No CAPTCHA" test compared to the other types of tests. However, there was no significant difference found in response times between this test and the Text-based, Picture-based and Game-based tests, although the action which needs to be taken in the "No CAPTCHA" test is significantly easier. Thus, this hypothesis was disproved unexpectedly. A possible explanation to this might be that the test does not end in all cases with merely checking the appropriate box by the caption 'I am not a robot'. There is a likely option that in many cases the test presented to the users the additional task (implemented in this test), which requires identifying letters and numbers similarly to the Text-based test, which caused the unexpected delay in performance times. Furthermore, it is possible that a certain delay could stem from a lack of understanding of the required task in the test, due to the absence of an explanation or of an explicit instruction. Another explanation might derive from the fact that this type of test, as of today, is novel, and the overwhelming majority of the participants reported that they had almost never encountered such a test. These results need further research. 
The age factor was encountered as influencing both the attitude of the user and the performance, although a reservation must be presented, giving that the frequency of the different ages is not balanced, and most of the respondents were in the 19-30 years old group.

The attitude towards the CAPTCHA tests was more negative for elder participants. Younger respondents are more tolerant towards "annoying" tasks through the Internet, while older users are more unpleasant and impatient towards these applications.

The results show that the response time increases along with the rise of age. This findings support the assertion made by Bursztein et al. (2010), who found that older users' performance times were longer than those of young users were.

The rate of success was higher for the youngest and lowest for the elders, contrary to the findings of Bursztein et al. (2010), that although users' response time grows longer with age, these older users also achieve higher success rates.

Thus, all hypotheses presented in RQ5 were accepted.

\section{Limitations and Further Research}

The main limitation of this study is that the participants' mother tongue is not English, although they are all familiar with Latin letters. This can affect the results, especially for the Text-based CAPTCHA test.

Further research is needed, especially for the "No CAPTCHA" test, which its findings left doubt and curiosity. For instance, it would be advisable to examine separately how many users were presented with an additional task to complete this test, and in what cases it is done.

Another recommendation for future research would be to examine the influence of different devices in solving CAPTCHA tests, e.g., through mobile phones or computers, on performance, and especially on user experience.

\section{Conclusion}

The objective of this study was to investigate the differences between various CAPTCHA tests and examine how they affect user experience. With this information, we can assess how to apply solutions that are more suitable for many users.

The main conclusion of this research is that all five types of tests influenced user experience in a certain level, from an experience of frustration to an experience of comfort and enjoyment. The success is not certain in any of the tests, so perhaps, users will need to perform the test more than once in order to receive access to the desired Website. This annoyance, and the time needed to perform the test, becomes an obstacle for users.

This paper will benefit organizations and firms which want to verify that those who enter their Website are real persons, but at the same time, not to exhaust them with difficult and confusing tests. Appropriate and careful reference to the findings and conclusions of this research, on behalf of user experience experts, developers, and web designers can lead in the future to evolving solutions applying usability that are more suitable for many users. Such solutions could both benefit significantly the accessibility on the Internet and improve the user experience on many websites.

\section{References}

Abrich, R., Berbenetz, V., \& Thorpe, M. (2011). Distinguishing between humans and robots on the web. Retrieved December 1, 2014, from richardabrich.com: http://richardabrich.com/abrich-berbenetzthorpe thecaptchaexperiment.pdf 


\section{CAPTCHA}

Ahn, Y., Kim, N., \& Kim, Y. S. (2013). A user-friendly image-text fusion CAPTCHA for secure web services. In Proceedings of International Conference on Information Integration and Web-based Applications \& Services, 550-554.

Angre, A. R., Kapadia, M. D., \& Ugale, M. (2015). PiCAPTion: Picture CAPTCHAs for internet authentication. International Journal of Computer Applications, 114(10).

Azad, K. J. (2013). Captcha: Attacks and weaknesses against OCR technology. Global Journal of Computer Science and Technology, 13(3).

Baltar, F., \& Brunet, I. (2012). Social research 2.0: Virtual snowball sampling method using Facebook. Internet Research, 22(1), 57-74.

Bhalani, S. D., \& Mishra, S. (2015). A survey on CAPTCHA technique based on drag and drop mouse action. International Journal of Technical Research and Applications, 3(2), 188-189.

Bevan, N. (2009). What is the difference between the purpose of usability and user experience evaluation methods. UXEM'09 Workshop, Upssala, Sweden.

Bursztein, E., Bethard, S., Fabry, C., Mitchell, J. C., \& Jurafsky, D. (2010). How good are humans at solving CAPTCHAs? A large scale evaluation. In Security and Privacy (SP), Symposium on Security and Privacy IEEE, 399-413.

Deterding, S., Dixon, D., Khaled, R., \& Nacke, L. (2011). From game design elements to gamefulness: defining gamification. In Proceedings of the 15th International Academic MindTrek Conference: Envisioning Future Media Environments (pp. 9-15). ACM.

Fidas, C., Voyiatzis, A., \& Avouris, N. . (2011). On the necessity of user-friendly CAPTCHA. In Proceedings of the SIGCHI Conference on Human Factors in Computing Systems, 2623-2626.

Foley, A. (2012, Jul). Biometric alternatives to CAPTCHA: Exploring accessible interface options. Masters Dissertation, Dublin Institute of Technology, Ireland.

Ghazarian, A. (2014). CAPTCHAs' effect on UX and how to fix it. Retrieved December 15, 2014, from DesignModo: http://designmodo.com/ux-captcha-effect

Gossweiler, R., Kamvar, M., \& Baluja, S. (2009). What's up CAPTCHA?: A CAPTCHA based on image orientation. In Proceedings of the 18th international conference on WWW, 841-850.

Hsu, C.-H., \& Lee, Y.-L. (2011). Effects of age groups and distortion types on text-based CAPTCHA tasks. In J. J. Jacko, Human-computer interaction. Users and Applications (pp. 435-455). New York: Springer-Verlag Berlin Heidelberg publications.

Ling-Zi, X., \& Yi-Chun, Z. (2012). A case study of text-based CAPTCHA attacks. In Cyber-Enabled Distributed Computing and Knowledge Discovery (CyberC), 2012 International Conference on (pp. 121-124). IEEE.

Mohamed, M., Sachdeva, N., Georgescu, M., Gao, S., Saxena, N., Zhang, C., \& Chen, W. B. (2013). Three-way dissection of a game-CAPTCHA: Automated attacks, relay attacks, and usability. Cornell University. New York: arXiv:1310.1540.

Mujumdar, D., \& Polisetti, S. (2011). A platform to monetize usable \& secure CAPTCHAs for desktop and mobile devices (PICATCHA). Retrieved Dec 20, 2014, from Kevinwarnock:

http://www.kevinwarnock.com/wpcontent/uploads/2012/05/picatcha_mims_final_report_summary_0.pdf

Onwudebelu, U., Sanjo, F., Obi, N. C., \& Alaba, O. B. (2010). CAPTCHA malaise: Users suffer consequences of the anti-spam technology while the spammers adapt. In Proceeding of the 1st International Conference and Workshop on Software Engineering and Intelligent Systems, 113-125.

ReCAPTCHA. (n.d.). In Wikipedia. Retrieved May 8, 2016, from https://en.wikipedia.org/wiki/ReCAPTCHA 
Saini, B. S., \& Bala, A. (2013). A review of bot protection using CAPTCHA for web security, IOSR Journal of Computer Engineering, 6, 36-42.

Singh, V. P., \& Pal, P. (2014). Survey of different types of CAPTCHA. International Journal of Computer Science and Information Technologies, 5(2), 2242-2245.

Symantec. (2011). MessageLabs Intelligence Report. Retrieved December 15, 2014, from Symantec: http://www.symanteccloud.com/mlireport/MLI_2011_05_May_FINAL-en.pdf

Tangmanee, C., \& Sujarit-apirak, P. (2013). Attitudes towards CAPTCHA: A survey of Thai internet users. The Journal of Global Business Management, 9, 29-41.

Tayade, P. C., \& Bartere, M. M. (2015). Comprehensive study on performance analysis of various CAPTCHA systems. International Journal of Current Engineering and Technology, 5(1)

Veesam, V. S., \& Babu, B. S. (2015). Evaluation of CAPTCHA technologies towards graphical password scheme evaluation. International Journal of Computer Engineering in Research Trends, 2(1), 98-106.

Wang, M., Zhang, T., Jiang, W., \& Song, H. (2014). The recognition of CAPTCHA. Journal of Computer and Communications, 2(02), 14.

\section{Biographies}

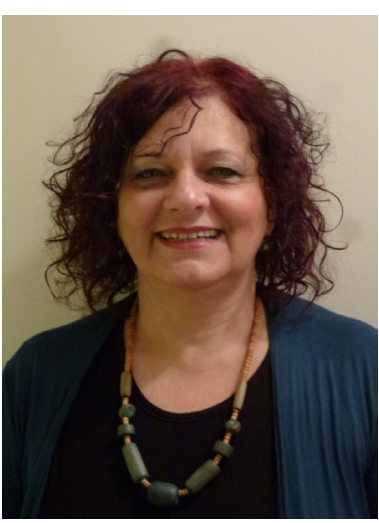

Ruti Gafni is the Head of the Information Systems B.Sc. program at The Academic College of Tel Aviv Yaffo. She holds a PhD from BarIlan University, Israel (in the Business Administration School), focusing on Information Systems, an M.Sc. from Tel Aviv University and a BA (Cum Laude) in Economics and Computer Science from Bar-Ilan University. She has more than 30 years of practical experience as Project Manager and Analyst of information systems. She also teaches in the Management and Economics MBA program at the Open University of Israel.

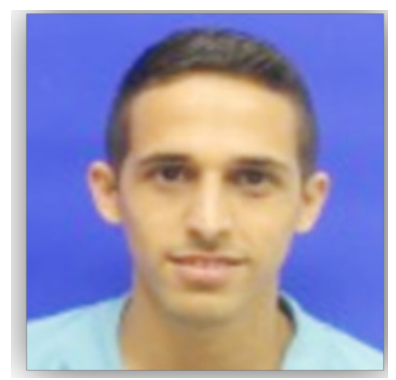

Idan Nagar is a student of the Information Systems B.Sc. program at The Academic College of Tel Aviv Yaffo. He worked as an Information Systems implementer, and served as a data analyst in the Israeli Air Force. Idan is a Mobile-Web developer, especially interested in Human-Computer Interaction and particularly in UI/UX design, development and measurement. 